\title{
Effects of cutter parameters on shearing stress for lettuce harvesting using a specially developed fixture
}

\author{
Yongjie Cui ${ }^{1,2,3}$, Wenqi Wang ${ }^{1}$, Minghui Wang ${ }^{1}$, Yidong Ma ${ }^{4 *}$, Longsheng $\mathrm{Fu}^{1,2,3^{*}}$ \\ (1. College of Mechanical and Electronic Engineering, Northwest A\&F University, Yangling 712100, Shaanxi, China; \\ 2. Key Laboratory of Agricultural Internet of Things, Ministry of Agriculture and Rural Affairs, Yangling 712100, Shaanxi, China; \\ 3. Shaanxi Key Laboratory of Agricultural Information Perception and Intelligent Service, Yangling 712100, Shaanxi, China; \\ 4. College of Agricultural Equipment Engineering, Henan University of Science and Technology, Luoyang 471003, Henan, China)
}

\begin{abstract}
To investigate the optimal parameters combination of reciprocating cutter for harvesting hydroponic lettuce automatically, a shear fixture was designed for cutting lettuce stems on a universal materials tester. Effects of blade distance, sliding cutting angle, skew cutting angle, and shearing angle on shearing stress were investigated in this study. The orders of the significance of a single factor and double factors were analyzed using the response surface methodology (RSM). A scanning electron microscope was used to observe the microstructure of the lettuce stem to analyze the shearing characteristics at the microscopic level. The RSM results showed that the order of significance for single factors was (i) sliding cutting angle, (ii) shearing angle, (iii) skew cutting angle, and (iv) blade distance. The sliding cutting angle had a highly significant influence on the shearing stress. The order of significance for double factors was (i) blade distance and shearing angle, (ii) sliding cutting angle and skew cutting angle, and (iii) the sliding cutting angle and shearing angle. A quadratic model of the factors and shearing stress was built according to the response-surface results. The optimized combination of factors that gives the minimum shearing stress was observed that it reduced $69.9 \%$ of the maximum shearing stress value. This research can provide a reference for designing lettuce-cutting devices.
\end{abstract}

Keywords: Lactuca sativa, hydroponic lettuce, cutting, optimization, response surface method, micro-structure DOI: $10.25165 /$ j.ijabe.20211404.6346

Citation: Cui Y J, Wang W Q, Wang M H, Ma Y D, Fu L S. Effects of cutter parameters on shearing stress for lettuce harvesting using a specially developed fixture. Int J Agric \& Biol Eng, 2021; 14(4): 152-158.

\section{Introduction}

Hydroponic lettuce is a common greenhouse vegetable whose production scale is increasing rapidly ${ }^{[1]}$. Nowadays, hydroponic lettuce (Lactuca sativa) is mainly manually harvested in China, with low efficiency and high labor costs ${ }^{[2]}$. Mechanized or automated harvesting is the most promising way to solve this issue $^{[3]}$.

Blade pattern, blade installation angle, and other cutter parameters of crop harvesters have an obvious influence on the harvesting quality. Cutter design is an extremely active area of crop harvesters ${ }^{[4,5]}$. Cho et al. ${ }^{[6]}$ developed a harvesting robot for hydroponic lettuce: a cylinder drove a blade to cut the lettuce, but the blade parameters were not studied. Igathinathane et al. ${ }^{[7]}$ studied the effect of orientation of corn stalks on mechanical cutting: the blade had a $30^{\circ}$ single-bevel sharp knife edge. To optimize the cutting-blade design of a sugarcane harvester,

Received date: 2020-12-07 Accepted date: 2021-03-19

Biographies: Yongjie Cui, $\mathrm{PhD}$, Professor, research interest: harvesting robot, Email: cuiyongjie@nwafu.edu.cn; Wenqi Wang, Master, research interest: lettuce harvesting machine, Email: dwq2018@nwafu.edu.cn; Minghui Wang, Master, research interest: lettuce cutting mechanism, Email: wangminghui@, nwafu.edu.cn.

*Corresponding author: Yidong Ma, PhD, Lecturer, research interest: lettuce harvesting mechanism. College of Agricultural Equipment Engineering, Henan University of Science and Technology, Xiyuan Road, Luoyang 471003, Henan Province, China. Tel: +86-15729108525, Email: mayidong90@163.com; Longsheng $\mathbf{F u}, \mathrm{PhD}$, Associate Professor, research interest: intelligent harvesting equipment. College of Mechanical and Electronic Engineering, Northwest A\&F University, Xinong Road, Yangling 712100, Shaanxi Province, China. Tel: +86-15502909963, Email: fulsh@nwafu.edu.cn.
Mathanker et al. ${ }^{[8]}$ investigated how the cutting speed and oblique blade angle affected the cutting energy. In China, the reciprocating cutters on rice and wheat harvesters, especially the standard blade and arrangement type of cutter, are often used as references for designing crop harvesters ${ }^{[9-13]}$. Reciprocating cutters have been used on commercial harvesters for lettuce planted in soil ${ }^{[14]}$

However, the existing reciprocating cutters on lettuce harvesters are unsuitable for harvesting hydroponic lettuce, because of agronomic conditions of hydroponics and soil culture are different. The stems of hydroponic lettuce are relatively short, and their physical properties differ obviously from those of long-stalked crops such as wheat. Besides, hydroponic lettuce should be harvested intact because leaf loss reduces the selling price. Therefore, cutting height is a necessary parameter for designing a lettuce harvester. Using traditional standard blade and cutter parameters for harvesting hydroponic lettuce would lead to a relatively large cutting device that would cause problems such as a significant cutting resistance and cutting too high. Therefore, foundational research is required for thinning blade patterns and installations that realize low-resistance cutting. Such research will provide a reference for designing lettuce-cutting devices.

Shearing characteristics of crop stalks have been used as references for designing cutting devices of harvester ${ }^{[15-25]}$. Ghahraei et al. ${ }^{[26]}$ selected knife edge angle, knife shear angle, knife approach angle, and knife rake angle as the test factors and studied how they affected the cutting force and cutting energy; a rotary impact cutting system was thus developed. A rotary cutter was used in the cabbage harvester, and the best cutting position and combination for cutting the cabbage roots were obtained. It 
showed that the best cutting combination was single point support, sliding cutting, downward inclining, and low cutting speed, while blade distance was not considered in the study. Chen et al. ${ }^{[27]}$ conducted laboratory experiments on a reciprocating cutter for cutting hemp, where the cutting force and energy for differing moisture content were measured. Ince et al. ${ }^{[28]}$ studied the shearing characteristics of sunflower stalks, taking the shearing stress as the test index to obtain the cutting force per unit area. Because the shearing force changed with different stalk diameters, selecting shearing stress as the test index could eliminate the influence of stalk diameter on the cutting force.

Some other studies were also conducted on crops planted in the greenhouse. Gao et al. ${ }^{[29]}$ designed a lettuce harvester and an experiment based on response surface methodology (RSM) to optimize the factors such as the cutting position and style. However, their cutter had no counter shear, and the characteristics of universal lettuce cutters have not yet been studied. The above foundational studies are mainly about how the factors such as the blade pattern and installation affect the shearing force and energy during blade cutting stalks. However, there are few studies about the comprehensive effects of blade shape parameter (namely sliding cutting angle) and the blade installation parameters (namely blade distance, skew cutting angle, and shearing angle) on the shearing stress for the reciprocating lettuce-cutting device. Moreover, there is little information available in the literature about the relationship between lettuce-stem microstructure and the shearing force characteristics.

To optimize the cutter parameters of hydroponic lettuce cutting device and study the shearing characteristics of lettuce stems, a shear fixture was designed in this study. Four test factors were selected, i.e., (i) the blade distance, (ii) the sliding cutting angle, (iii) the skew cutting angle, and (iv) the shearing angle. An RSM test was designed to study the order of significance of these factors and their optimized combination. A scanning electron microscope (SEM) was used to observe the microstructure of the lettuce stem and analyze the shearing process at the microscopic level. It will provide a reference for designing and improving miniaturized lettuce-cutting devices.

\section{Materials and methods}

Naiyou variety of hydroponic lettuce was used in the experiment. The lettuces were cultivated for $45 \mathrm{~d}$ in a plant factory (Xutian Photoelectric Co., Ltd, Xi' an, China). A total of 100 lettuces were selected randomly, where 90 of them were used for the RSM tests (divided into 30 groups containing three lettuces each) and the remaining of them were used for the verification tests. Leaves and roots were removed manually to obtain lettuce stems as the experimental samples (Figure 1), which had diameters of 14 to $20 \mathrm{~mm}$.

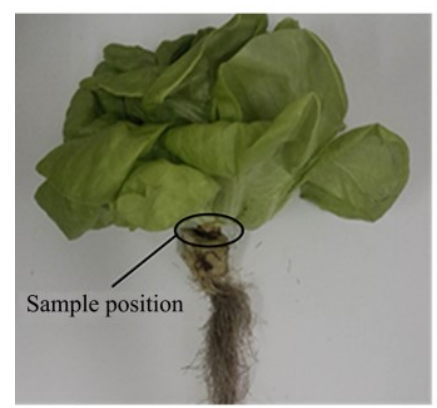

a. Test material

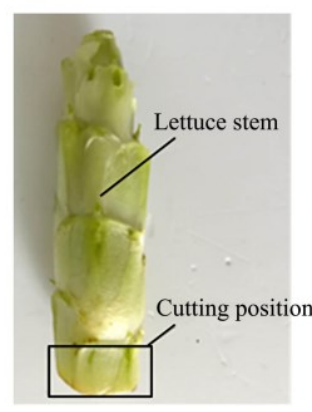

b. Sample preparation
Figure 1 Test material and sample preparation

\subsection{Design of shear fixture and operating principle}

To measure the shearing force of the lettuce stem, a shear fixture was designed to work on a universal materials tester (HY-0230, Shanghai Hengyi Testing Instruments Co., Ltd, China). The system for measuring the shearing force is shown in Figure 2, where the maximum shearing force could reach $100 \mathrm{~N}$. To measure the shearing force as accurately as possible, the cutting speed used was $50 \mathrm{~mm} / \mathrm{min}^{[30]}$.

The blade distance between the edge and the counter shear influenced the stem stiffness when the cutting combination was set constantly as single-point clamping. The blade distance was changed by moving the blade distance adjustment plate (Figure $2 b$ ).

The sliding angle was an important parameter that influences the blade shape $e^{[16,30]}$, and blade velocity was inclining with the blade edge due to the influence of the sliding angle. During sliding cutting, the blade velocity could be resolved into the sliding cutting velocity and the hewing velocity, which were parallel and perpendicular to the blade edge, respectively. The sliding angle was the tilt angle of the blade edge, which was the angle between the sliding cutting velocity and the hewing velocity. The blade was installed on two plates, and the sliding angle could be adjusted by regulating the blade installation site on the sliding cutting angle adjustment plate (Figure $2 b$ ).

The skewing cutting angle was the angle between the cutting face and the stem axis. Skewing cutting was when the cutting face was inclining with the stem axis, while the cutting direction was perpendicular to the stem axis. The skew cutting angle was regulated by revolving the installing angle of the skew cutting angle adjustment plate (Figure $2 b$ ).

The shearing angle was defined as that between the cutting direction and the stem axis. When the cutting face of the blade was inclining with the stem axis, the shearing angle was set by revolving the installing angle of the stem fixture on shearing angle adjustment brackets (Figure $2 b$ ).

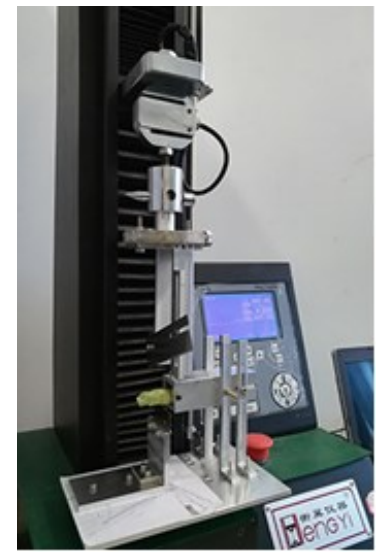

a. Shearing-force measurement platform

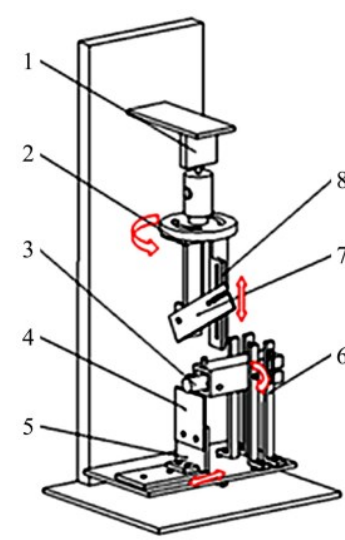

b. Diagram of shear fixture
1. Force sensor 2. Skew-cutting-angle adjustment plate 3. Lettuce stem 4. Counter shear 5. Blade distance adjustment plate 6. Shearing-angle adjustment bracket 7 . Blade 8 . Sliding-cutting-angle adjustment plate.

Figure 2 Measurement system of shearing force

\subsection{Scanning electron microscopy}

To analyze the shearing characteristics of lettuce stems from a microstructural perspective, the matrix and epidermis of a lettuce stem were scanned by SEM (TM3030; Hitachi, Ltd., Japan). The following are the steps to prepare a sample for SEM scanning: 1) A transverse section and a longitudinal section of a lettuce stem were made, and the thickness of the specimens was $1 \mathrm{~mm}$; 2) To avoid deterioration of the ultra-structure of the specimen surface, the specimens were freeze-dried for $6 \mathrm{~h}$ in a freeze-drying device 
(SJIA-12N, Ningbo Sjialab Equipment Co., Ltd., China) at a drying temperature of $\left.-50^{\circ} \mathrm{C} ; 3\right)$ to improve the efficiency of generating secondary electrons and prevent the specimens from being charged during the SEM observation, the surface of specimens was coated with $\mathrm{Au}$ and Pd using a metal coating apparatus (MSP-2S, IXRF Systems, Inc., USA).

To observe the microstructures of the matrix and epidermis, the image magnification was set as $100 \times$. The microstructure character of the matrix was observed from the transverse section and longitudinal section. The image magnification of matrix pictures was $1000 \times$ to observe the microstructure more clearly.

\section{Mechanical tests}

The smooth-edged blade used in the RSM test was made of a $0.5 \mathrm{~mm}$ thick carbon steel with a $60^{\circ}$ blade edge. The fixture clamped the lettuce stem with a single-point clamping way. Shearing force-displacement curve that revealed the shearing process of lettuce stem was obtained by the universal materials tester. The accuracy of the load cell was $0.3 \%$, and the data sampling frequency was $50 \mathrm{~Hz}$. The stroke and speed accuracies were both $\pm 0.5 \%$ of the indicated value.

\subsection{Ranges of test-factor values}

Blade distance, sliding cutting angle, skew cutting angle, and shearing angle were chosen as the test factors. From a preparatory experiment, the blade distance range of 0.5 to $2.5 \mathrm{~mm}$ was chosen. From a previous study ${ }^{[9]}$, the sliding-cutting-angle range of $0^{\circ}$ to $40^{\circ}$ was selected. The skew cutting angle and the shearing angle are the reference bases for the inclination angle of the cutter. Due to the short stem used, the blade would damage the lettuce leaves if the skew cutting angle or shearing angle was too large. Based on the requirements of lettuce harvesting, the range of values for skewing-angle and shearing-angle was set from $0^{\circ}$ to $20^{\circ}$.

\subsection{Test index}

Because the shearing force changed with different lettuce stem diameters, shearing stress was chosen as the index according to previous studies ${ }^{[17,28,31]}$, and the shearing stress showed the shearing force per unit area. The shearing force measurement system (Figure 2) could measure only the shearing force, and the shearing stress $\tau$ (in megapascals) was calculated by Equation $(1)^{[28]}$.

$$
\tau=F_{\max } / S
$$

where, $F_{\max }$ is the maximum shearing force, $\mathrm{N} ; S$ is the cross-sectional area of the stem at a shearing plane, $\mathrm{mm}^{2}$. The profile of stem cross-sectional was depicted on graph paper, then the area was measured by the graph paper.

\subsection{Design of RSM test}

To obtain (i) the combination of factors that gave the minimum shearing stress, (ii) the order of significance of the factors, and (iii) how the factors affected the shearing stress, an RSM test using the central composite inscribed (CCI) method was designed and conducted in Design-Expert 7.0 software (Stat-Ease, Inc., USA). The four factors were the blade distance (factor $A$ ), the sliding cutting angle (factor $B$ ), the skew cutting angle (factor $C$ ), and the shearing angle (factor $D$ ). To ensure the factor levels in the range of test-factor values, the alpha (the distance between Lower level and Zero level) was set as 0.5 in the software, and the coding of the factor levels was calculated by the software (Table 1). The calculation of Design-Expert showed that there were 30 test runs. Repeated each run three times and recorded the mean shearing stress as a result of that run.
Table 1 Coding of shearing factor levels

\begin{tabular}{lcccc}
\hline \multirow{2}{*}{ Level } & \multicolumn{4}{c}{ Factors } \\
\cline { 2 - 5 } & $A / \mathrm{mm}$ & $B /\left(^{\circ}\right)$ & $C /\left(^{\circ}\right)$ & $D /\left(^{\circ}\right)$ \\
\hline Lower asterisk arm $(-1)$ & 0.5 & 0 & 0 & 0 \\
Lower level (-0.5) & 1 & 10 & 5 & 5 \\
Zero level (0) & 1.5 & 20 & 10 & 10 \\
Upper level (0.5) & 2 & 30 & 15 & 15 \\
Upper asterisk arm (1) & 2.5 & 40 & 20 & 20 \\
\hline
\end{tabular}

Note: $A$ : the blade distance; $B$ : the sliding cutting angle; $C$ : the skew cutting angle; $D$ : the shearing angle.

\section{Results and discussion}

\subsection{Lettuce-stem microstructure and shearing force- displacement curve}

The microstructure of the lettuce stem comprised mainly epidermis and matrix (Figure 3). The epidermis was composed primarily of fibers wrapped tightly around the matrix. The matrix was composed of parenchyma cell walls, which were arranged in fascicular clusters with cavities; the thin cell walls formed the vascular tissue (Figure 4). The lettuce-stem microstructure (Figures 3 and 4) was similar to that of cabbage roots, as reported by $\mathrm{Du}$ et al. ${ }^{[30]}$. The microstructural characteristics of the fibers and the parenchyma cell walls and cavities were likely to affect the shearing force. Figures 3 and 4 showed that the force to cut the epidermis fibers is relatively high, while the force to cut the matrix is relatively low. The SEM images and the shearing force-displacement curve made it possible to analyze the shearing process at the microscopic level.

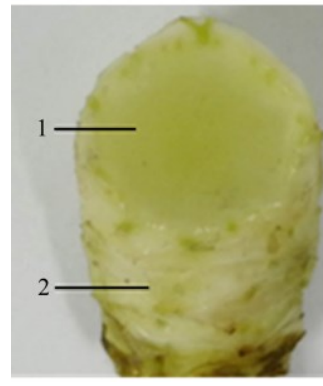

a. Lettuce stem

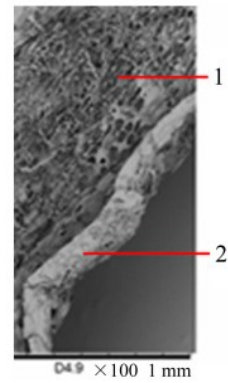

b. SEM image $(100 \times$ magnification $)$
1. Matrix 2. Epidermis

Figure 3 Lettuce stem and its SEM image $(100 \times$ magnification $)$

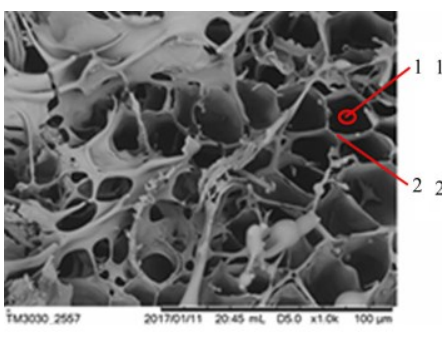

a. Transverse section

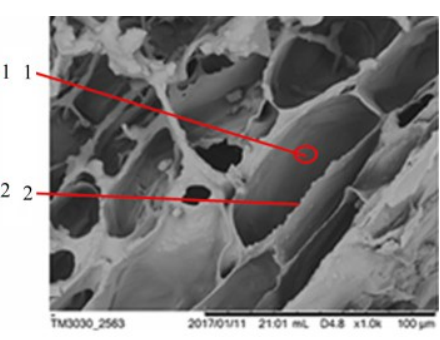

b. Longitudinal section
1. Cavity 2. Parenchyma cell wall

Figure 4 SEM images of stem matrix (1000× magnification)

Figure 5 shows a typical shearing force-displacement curve, the conditions being a blade distance of $1.5 \mathrm{~mm}$, a sliding cutting angle of $20^{\circ}$, a skew cutting angle of $15^{\circ}$, a shearing angle of $10^{\circ}$, and a cutting-position area of $180 \mathrm{~mm}^{2}$. A typical curve (Figure 5a) had two peaks and could be divided into three distinct sections that represent 1) the initial stage of shearing (from the start point $H$ to the first peak $I$ ); 2) the interim stage of shearing (from the first peak $I$ to the final peak $J$ ); and 3 ) the final stage of shearing (from 
the final peak $J$ to the failure point $K$ ). The typical shearing force-displacement curve (Figure 5) with its two peaks and three distinct sections was similar to the process of shearing hemp, sunflower stalks, and corn stalks ${ }^{[7,27,28]}$. In Figure 5, the shearing force increased from the start point $H$ to the first peak $I$ with the cut dense fibrous epidermis tissue (Figure $3 b$ ), reaching the maximum width. Once the blade had passed the point $I$, both the epidermis and the matrix were being cut, and only the dense fibrous tissues remain on either side of the epidermis. Because the matrix contained many cavities (Figure 4), the shearing force decreases, and the curve became smoother. When the blade reached point $J$ (Figure 5b), the cut dense fibrous epidermis tissue (the cut position was at point $J$ shown in Figure 5 b) turned the maximum again. Hence, the shearing force reached the second peak (Figure 5a). Once the blade has passed point $J$, the force drops with the epidermis cut by the blade turning smaller, and the shearing was complete when the blade reaches point $K$. The shearing force-displacement curve showed that the position of maximum force was related not only to the blade travel but also to the structural characteristics of the lettuce stem (Figures 3 and 4). The maximum force occurs where the fibrous epidermis tissue was most dense, which was in accord with previous studies ${ }^{[16,27,28,30]}$.

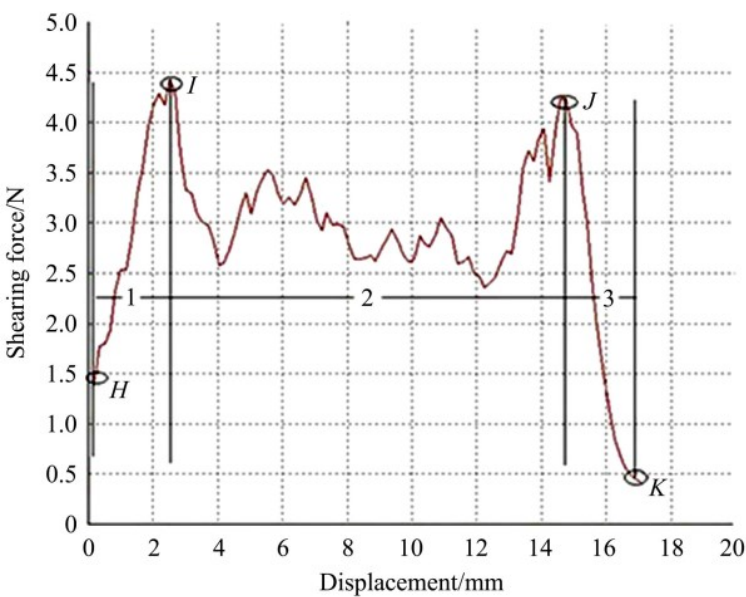

a. Displacement curve

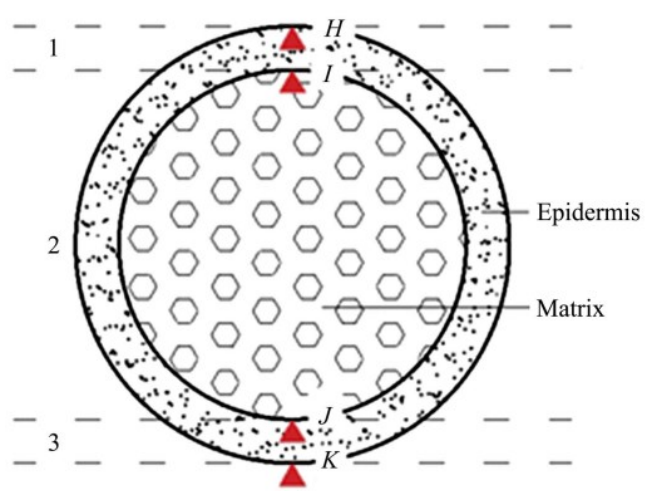

b. Transverse diagram of lettuce stem

Figure 5 Typical shearing force-displacement curve (a) and transverse diagram of lettuce stem (b)

\subsection{Results of the RSM test}

Table 2 gave the results of the RSM test (30 runs). The maximum and minimum of shearing stress among the 30 runs were $3.9321 \times 10^{4} \mathrm{~Pa}$ (test group 8) and $1.2217 \times 10^{4} \mathrm{~Pa}$ (test group 24), respectively. They were significantly larger or smaller than other groups.

From these results (Table 2), a quadratic polynomial model for the four factors and the shearing stress was built by the
Design-Expert, as shown in Equation (2). The $R^{2}$ for the quadratic model was 0.8695 .

$$
\begin{aligned}
\tau= & 4.11956-0.32007 a+0.077169 b-0.036300 c \\
& -0.22832 d+0.026758 a d+8.66188 \times 10^{-4} b c+ \\
& 6.95125 \times 10^{-4} b d-3.16294 \times 10^{-3} b^{2}+7.49024 \times 10^{-3} d^{2}
\end{aligned}
$$

where, $\tau$ is the value of the shearing stress; $a, b, c$, and $d$ are values of blade distance (factor $A$ ), sliding angle (factor $B$ ), skew cutting angle (factor $C$ ), and shearing angle (factor $D$ ), respectively.

\begin{tabular}{|c|c|c|c|c|c|}
\hline \multirow{2}{*}{$\begin{array}{l}\text { Test } \\
\text { group }\end{array}$} & \multicolumn{4}{|c|}{ Factors } & \multirow{2}{*}{$\begin{array}{c}\text { Shearing stress } \tau \text { (mean } \\
\text { value } \pm \text { standard } \\
\left.\text { deviation) } / \times 10^{4} \mathrm{~Pa}\right)\end{array}$} \\
\hline & $A / \mathrm{mm}$ & $B /\left(^{\circ}\right)$ & $C /\left({ }^{\circ}\right)$ & $D /\left(^{\circ}\right)$ & \\
\hline 1 & 2.5 & 0 & 0 & 20 & $3.4296 \pm 0.0262^{1}$ \\
\hline 2 & 2.5 & 0 & 20 & 0 & $2.5618 \pm 0.1198^{\mathrm{f}}$ \\
\hline 3 & 1.5 & 20 & 10 & 10 & $2.9339 \pm 0.0786^{\text {ghi }}$ \\
\hline 4 & 1.5 & 20 & 5 & 10 & $2.9694 \pm 0.0374^{\text {ghij }}$ \\
\hline 5 & 1.5 & 20 & 10 & 15 & $2.8055 \pm 0.3092^{\mathrm{g}}$ \\
\hline 6 & 1.5 & 20 & 10 & 10 & $3.0085 \pm 0.0258^{\mathrm{hijk}}$ \\
\hline 7 & 1.5 & 10 & 10 & 10 & $3.0935 \pm 0.1149^{\mathrm{ijk}}$ \\
\hline 8 & 0.5 & 0 & 0 & 0 & $3.9321 \pm 0.0510^{\mathrm{m}}$ \\
\hline 9 & 1.5 & 30 & 10 & 10 & $1.5880 \pm 0.0794^{\mathrm{c}}$ \\
\hline 10 & 1.5 & 20 & 10 & 10 & $3.1805 \pm 0.0749^{\mathrm{k}}$ \\
\hline 11 & 0.5 & 40 & 20 & 20 & $1.3781 \pm 0.0667^{\mathrm{ab}}$ \\
\hline 12 & 1.5 & 20 & 10 & 10 & $2.4408 \pm 0.0387^{\mathrm{f}}$ \\
\hline 13 & 1.5 & 20 & 10 & 5 & $2.8831 \pm 0.0997^{\text {gh }}$ \\
\hline 14 & 2.5 & 40 & 20 & 0 & $1.5286 \pm 0.0323^{\mathrm{bc}}$ \\
\hline 15 & 1.5 & 20 & 10 & 10 & $2.9677 \pm 0.0411^{\text {ghij }}$ \\
\hline 16 & 1.5 & 20 & 15 & 10 & $2.4725 \pm 0.0429^{\mathrm{f}}$ \\
\hline 17 & 0.5 & 0 & 20 & 0 & $3.4136 \pm 0.0544^{1}$ \\
\hline 18 & 0.5 & 40 & 20 & 0 & $1.6767 \pm 0.0843^{\mathrm{c}}$ \\
\hline 19 & 0.5 & 40 & 0 & 0 & $2.0160 \pm 0.0343^{\mathrm{de}}$ \\
\hline 20 & 2.5 & 40 & 0 & 20 & $1.5673 \pm 0.0857^{\mathrm{c}}$ \\
\hline 21 & 0.5 & 0 & 0 & 20 & $2.4032 \pm 0.0831^{\mathrm{f}}$ \\
\hline 22 & 2.5 & 0 & 0 & 0 & $3.1250 \pm 0.1030^{\mathrm{ijk}}$ \\
\hline 23 & 2.5 & 0 & 20 & 20 & $2.1927 \pm 0.0940^{\mathrm{e}}$ \\
\hline 24 & 0.5 & 40 & 0 & 20 & $1.2217 \pm 0.0092^{\mathrm{a}}$ \\
\hline 25 & 2 & 20 & 10 & 10 & $2.0917 \pm 0.1195^{\mathrm{e}}$ \\
\hline 26 & 2.5 & 40 & 0 & 0 & $1.5090 \pm 0.0610^{\mathrm{bc}}$ \\
\hline 27 & 1 & 20 & 10 & 10 & $3.1305 \pm 0.2531^{\mathrm{jk}}$ \\
\hline 28 & 0.5 & 0 & 20 & 20 & $1.8946 \pm 0.1520^{\mathrm{d}}$ \\
\hline 29 & 2.5 & 40 & 20 & 20 & $1.6752 \pm 0.0711^{\mathrm{c}}$ \\
\hline 30 & 1.5 & 20 & 10 & 10 & $2.4148 \pm 0.0786^{\mathrm{f}}$ \\
\hline
\end{tabular}

Table 2 Results of the RSM test (each group was repeated three times)

The analysis of variance (ANOVA) for the quadratic model (Table 3) showed that the model of regression equation was significant $(p<0.0001)$, and the lack of fit of the regression equation was insignificant $(p=0.5678)$, meaning that the model could be used to find the optimal combination of factors and their order of significance. The order of significance of the single factors was (i) the sliding cutting angle, (ii) the shearing angle, (iii) the skew cutting angle, and (iv) the blade distance, where the $p$ values of the factors were $<0.0001,0.0049,0.0236$, and 0.5057 , respectively. The sliding cutting angle had a remarkable influence on the shearing stress. The order of significance of double factors was (i) the blade distance and shearing angle, (ii) the sliding cutting angle and skewed cutting angle, and (iii) the sliding cutting angle and shearing angle, where the $p$ values were $0.0028,0.0395$, and 0.0942 , respectively. 


\subsection{Effect of significant factors on shearing stress}

The ANOVA results (Table 3) show that the sliding cutting angle (factor $B$ ) had a highly significant influence on the shearing stress among the single factors and the combination of blade distance and shearing angle (factors $A$ and $D$ ) was the most notable of the double factors. Therefore, it was necessary to analyze how these factors affect the shearing stress.

Table 3 Analysis of variance (ANOVA) of the quadratic model

\begin{tabular}{cccccc}
\hline Source & Sum of squares & Freedom & Mean square & $F$ value & $p$ value \\
\hline Model & 13.19 & 9 & 1.47 & 14.81 & $<0.0001$ \\
$a$ & 0.045 & 1 & 0.045 & 0.46 & 0.5057 \\
$b$ & 7.51 & 1 & 7.51 & 75.88 & $<0.0001$ \\
$c$ & 0.59 & 1 & 0.59 & 6.00 & 0.0236 \\
$d$ & 0.99 & 1 & 0.99 & 9.99 & 0.0049 \\
$a d$ & 1.15 & 1 & 1.15 & 11.57 & 0.0028 \\
$b c$ & 0.48 & 1 & 0.48 & 4.85 & 0.0395 \\
$b d$ & 0.31 & 1 & 0.31 & 3.12 & 0.0924 \\
$b^{2}$ & 0.40 & 1 & 0.40 & 4.01 & 0.0591 \\
$d^{2}$ & 0.14 & 1 & 0.14 & 1.40 & 0.2499 \\
Residual & 1.98 & 20 & 0.099 & & \\
Lack of fit & 1.47 & 15 & 0.098 & 0.97 & 0.5678 \\
Pure error & 0.51 & 5 & 0.10 & & \\
Total & 15.17 & 29 & & & \\
\hline
\end{tabular}

To analyze how the sliding cutting angle affects the shearing stress, the factors in Table 2 were selected. All the runs were with the same values for factors $A, C$, and $D$, while different values for factor B. The results (Figure 6) showed that the shearing stress (when the sliding cutting angle was $40^{\circ}$ ) was smaller than that of $0^{\circ}$. The cutting state was known as hewing when the sliding cutting angle was $0^{\circ}$ and sliding cutting when the sliding cutting angle was other than $0^{\circ}$. The shearing stress associated with sliding cutting was smaller than that associated with hewing; this agrees with the findings of Cheng et al. ${ }^{[9]}$, who reported on how the sliding cutting angle of a reciprocating bush cutter affected the cutting force.

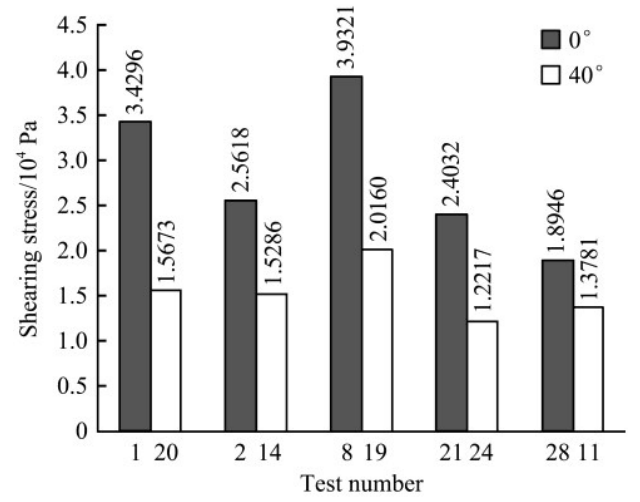

Figure 6 Effect of sliding cutting angle on shearing stress

The shearing stress associated with sliding cutting was smaller than that associated with hewing due to the influence of the sliding cutting velocity on the blade edge (Figure 7). Because of the influence of the sliding cutting angle $\beta$, the blade velocity $V$ could be decomposed into $V_{n}$ and $V_{t}$, which are perpendicular and parallel to the blade edge, respectively (Figure 7a). Because $V_{t}=V \sin \beta$, so $V_{t}$ increased as the sliding cutting angle increased from $0^{\circ}$ to $40^{\circ}$. The edge angle of the blade changed because of the influence of the sliding cutting angle (Figure $7 \mathrm{~b}$ ). The blade velocity in the hewing state was defined as $V_{0}$, so the edge angle of the blade was $\alpha=\angle \mathrm{OMQ}$ (Figure 7b). Under the sliding-cutting state, the blade velocity changed to $V_{1}$, and $\alpha$ changed to $\angle \mathrm{TME}$ (Figure $7 \mathrm{~b}$ ). Results showed that $\angle \mathrm{TME}$ was smaller than $\angle \mathrm{OMQ}$, meaning that the edge angle decreased in the sliding-cutting state, and the blade edge became effectively sharper. Therefore, the lettuce-stem shearing stress was lower with sliding cutting.

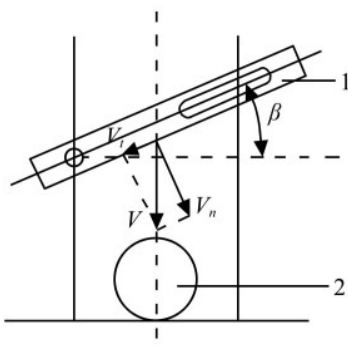

a. Velocity resolution

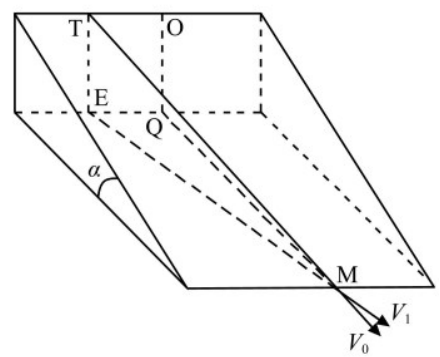

b. Variation of edge angle
Figure 7 Blade-velocity resolution and edge-angle variation under sliding cutting

Figure 8 shows how the interaction of factors $A$ and $D$ affected the shearing stress, where the sliding cutting angle and skew cutting angle being $20^{\circ}$ and $10^{\circ}$, respectively. Besides, the shearing angle had a more evident effect on the shearing stress than the blade distance under the $A-D$ interaction. As the shearing angle increased, the shearing stress first decreased and then increased, reaching its minimum value at a shearing angle of around $10^{\circ}$. Therefore, the best installation shearing angle for a lettuce-harvester cutter was around $10^{\circ}$ under the above interaction conditions. The effect of shearing angle on the shearing stress was consistent with Du et al. ${ }^{[30]}$ that downward inclining mode was one way to decrease the force required to cut cabbage roots.

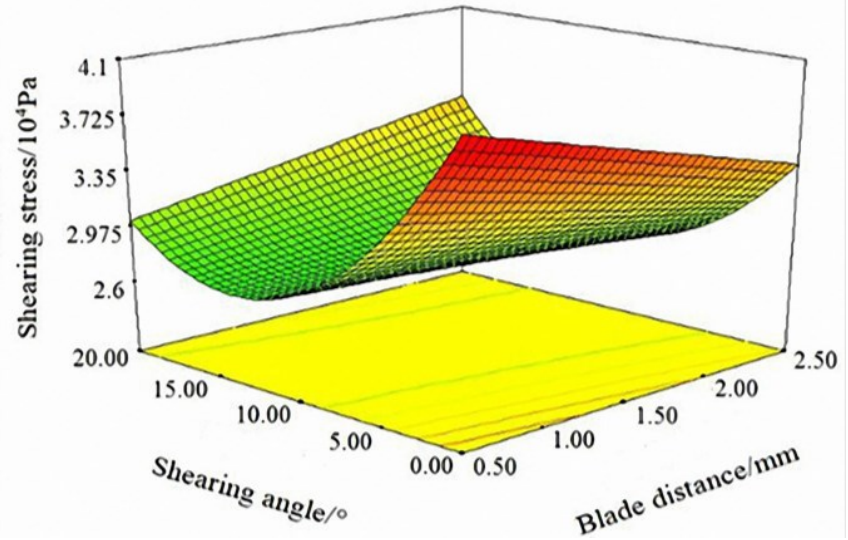

Figure 8 Response surface for factors $A$ and $D$ and shearing stress

\subsection{Optimal factor combination and test verification}

To obtain the optimal combination of factors that minimizes the shearing stress, the optimization function of the Design-Expert software was applied. Various optimal combinations were found, and the one with the lowest shearing stress (namely $0.8026 \times 10^{4} \mathrm{~Pa}$ ) was a combination of blade distance, sliding cutting angle, skew cutting angle, and shearing angle with $1.66 \mathrm{~mm}, 39.88^{\circ}, 12.99^{\circ}$, and $11.15^{\circ}$, respectively. A test was conducted to verify this software-based result, repeating it by ten times (Table 4). The shearing stress was $1.1852 \times 10^{4} \mathrm{~Pa}$ in average with a standard deviation of $73 \mathrm{~Pa}$, and a coefficient of variation was $0.62 \%$. The conditions of the verification test solved by the Design-Expert were precise, so the result of the verification test differs slightly from that of the software. The average shearing stress of $1.1852 \times$ $10^{4} \mathrm{~Pa}$ in the present study is less than that (cutting force $17.4 \mathrm{~N}$, and diameter range $8.0-16.5 \mathrm{~mm}$ ) reported by Gao et al. ${ }^{[29]}$. They 
optimized the factors of a lettuce harvester without considering the influence of the sliding cutting angle.

Table 4 Results of verification test

\begin{tabular}{cccc}
\hline $\begin{array}{c}\text { Test } \\
\text { number }\end{array}$ & $\begin{array}{c}\text { Maximum of } \\
\text { shearing force/ }\end{array}$ & $\begin{array}{c}\text { Sectional area } \\
/ \mathrm{mm}^{2}\end{array}$ & $\begin{array}{c}\text { Shearing stress } \\
/ \times 10^{4} \mathrm{~Pa}\end{array}$ \\
\hline 1 & 2.275 & 191 & 1.1911 \\
2 & 3.429 & 291 & 1.1784 \\
3 & 2.177 & 182 & 1.1962 \\
4 & 3.31 & 281 & 1.1779 \\
5 & 2.581 & 216 & 1.1949 \\
6 & 3.362 & 286 & 1.1755 \\
7 & 3.278 & 276 & 1.1877 \\
8 & 2.912 & 246 & 1.1837 \\
9 & 3.111 & 265 & 1.1740 \\
10 & 2.618 & 221 & 1.1846 \\
\hline
\end{tabular}

The test of the maximum shearing stress $\left(3.9321 \times 10^{4} \mathrm{~Pa}\right)$ in the RSM test was chosen as the control group, and the shearing stress was when the corresponding blade distance, sliding cutting angle, skew cutting angle, and shearing angle were $0.5 \mathrm{~mm}, 0^{\circ}, 0^{\circ}$, and $0^{\circ}$, respectively (No. 8 in Table 2). The shearing stress of the optimal combination was reduced by $69.9 \%$ compared to the control group, which shows an obvious optimization. Decreasing the shearing stress could provide a basis for designing a smaller cutting device, which could, in turn, ensure blade cutting the short stems of hydroponic lettuce. The optimal combination of factors presented herein could act as a reference for designing a miniaturized lettuce-cutting device.

\section{Conclusions}

A shear fixture was designed for providing a method to regulate blade distance, sliding cutting angle, skew cutting angle, and shearing angle. RSM was employed to optimize the cutter parameters. The typical shearing force-displacement curve has two peaks, and the maximum shearing force appears where the dense fibrous epidermis tissue is the biggest. The single-factor order of significance was (i) sliding cutting angle (factor $B$ ), (ii) shearing angle (factor $D$ ), (iii) skew cutting angle (factor $C$ ), and (iv) blade distance (factor $A$ ). The sliding cutting angle had a highly significant influence on the shearing stress. The double-factor order of significance was (i) the blade distance and shearing angle $(A-D)$, (ii) the sliding cutting angle and skew cutting angle $(B-C)$, and (iii) the sliding cutting angle and shearing angle $(B-D)$. The optimal combination of factors was a blade distance of $1.66 \mathrm{~mm}$, a sliding cutting angle of $39.88^{\circ}$, a shearing angle of $11.15^{\circ}$, and a skew cutting angle of $12.99^{\circ}$. It gave minimum shearing stress of $1.1852 \times 10^{4} \mathrm{~Pa}$, which reduced $69.9 \%$ shearing stress than the maximum shearing stress.

\section{Acknowledgements}

This research was supported by the Key Research and Development Program in Shaanxi Province of China (Grant No. 2018TSCXL-NY-05-04, 2019ZDLNY02-04); Science and Technology Program in Yulin City of China (Grant No. CXY-2020-076).

\section{[References]}

[1] Suo R, Wang W Q, Ma Y D, Fu L S, Cui Y J. Effect of different root lengths for retaining freshness of hydroponic lettuce. J. Agric. Food Res., 2021; 4: 100151. doi: 10.1016/j.jafr.2021.100151.
[2] Ma Y D, Xu C, Cui Y J, Fu L S, Liu H Z, Yang C. Design and test of harvester for whole hydroponic lettuce with low damage. Transactions of the CSAM, 2019; 50(1): 162-169. (in Chinese)

[3] Fu L S, Feng Y L, Wu J Z, Liu Z H, Gao F F, Majeed Y, et al. Fast and accurate detection of kiwifruit in orchard using improved YOLOv3-tiny model. Precis Agric., 2021; 22(3): 754-776.

[4] Brown D, Glancey J L. Theoretical and experimental analysis of a continuous-blade cutting system for leafy vegetables. Transactions of the ASABE, 2007; 50(3): 803-813.

[5] Chen Z G, Wang D F, Li L Q, Shan R X. Experiment on tensile and shearing characteristics of rind of corn stalk. Transactions of the CSAE, 2012; 28(21): 59-65.

[6] Cho S I, Chang S J, Kim Y Y, An K J. AE-Automation and emerging technologies: development of a three-degrees-of-freedom robot for harvesting lettuce using machine vision and fuzzy logic control. Biosyst. Eng., 2002; 82(2): 143-149.

[7] Igathinathane $\mathrm{C}$, Womac A R, Sokhansanj S. Corn stalk orientation effect on mechanical cutting. Biosyst. Eng., 2010; 107(2): 97-106.

[8] Mathanker S K, Grift T E, Hansen A C. Effect of blade oblique angle and cutting speed on cutting energy for energycane stems. Biosyst. Eng., 2015; 133: 64-70.

[9] Cheng C, Yu G S. Effect of sliding cutting angle of bush reciprocating cutter on bush cutting. J. Beijing Forest Univ., 2011; 33(2): 115-119. (in Chinese)

[10] Du D D, Wang J. Research on mechanics properties of crop stalks: A review. Int J Agric \& Biol Eng, 2016; 9(6): 10-19.

[11] Wang Y, Yang Y, Zhao H M, Liu B, Ma J T, He Y, et al. Effects of cutting parameters on cutting of citrus fruit stems. Biosyst. Eng., 2020; 193: 1-11.

[12] Xu Y F, Zhang X L, Sun X J, Wang J Z, Liu J Z, Li Z G, et al. Tensile mechanical properties of greenhouse cucumber cane. Int J Agric \& Biol Eng, 2016; 9(5): 1-8.

[13] Zhao J L, Huang D Y, Jia H L, Zhuang J, Guo M Z. Analysis and experiment on cutting performances of high-stubble maize stalks. Int $\mathrm{J}$ Agric \& Biol Eng, 2017; 10(1): 40-52.

[14] Nang V N, Yamane S. Development of prototype harvester for head lettuce. Eng. Agric. Environ. Food, 2015; 8(1): 18-25.

[15] Dowgiallo A. Cutting force of fibrous materials. J. Food Eng., 2005; 66(1): 57-61.

[16] Du D D, Wang J, Qiu S S. Analysis and test of splitting failure in the cutting process of cabbage root. Int J Agric \& Biol Eng, 2015; 8(4): $27-34$.

[17] Galedar M N, Jafari A, Mohtasebia S S, Tabatabaeefar A, Sharifi A, O'Dogherty M J, et al. Effects of moisture content and level in the crop on the engineering properties of alfalfa stems. Biosyst. Eng., 2008; 101(2): 199-208.

[18] Guarnieri A, Maglioni C, Molari G. Dynamic analysis of reciprocating single-blade cutter bars. Transactions of the ASABE, 2007; 50(3): 755-764.

[19] Jia H L, Li C Y, Zhang Z H, Wang G. Design of bionic saw blade for corn stalk cutting. J. Bionic Eng., 2013; 10(4): 497-505.

[20] Johnson P C, Clementson C L, Mathanker S K, Grift T E, Hansen A C. Cutting energy characteristics of miscanthus $\times$ giganteus stems with varying oblique angle and cutting speed. Biosyst. Eng., 2012; 112(1): 42-48.

[21] Liu Q, Mathanker S K, Zhang Q, Hansen A C. Biomechanical properties of misscanthus stems. Transactions of the ASABE, 2012; 55(4): $1125-1131$.

[22] Newman J M, Hilton H W, Clifford S C, Smith A C. The mechanical properties of lettuce: A comparison of some agronomic and postharvest effects. J. Mater. Sci., 2005; 40(5): 1101-1104.

[23] Gao F F, Fu L S, Zhang X, Majeed Y, Li R, Karkee M, et al. Multi-class fruit-on-plant detection for apple in SNAP system using Faster R-CNN. Comput. Electron. Agric., 2020; 176: 105634 doi: 10.1016/j.compag.2020.105634.

[24] Shepardson E S, Pollock J G, Rehkugler G E. Research and development of a lettuce harvester. Transactions of the ASAE, 1974; 17(2): 212-216.

[25] Uchida T, Yamano T, Miyazaki H. Development on automatic harvesting system for leaf vegetables. Shokubutsu Kojo Gakkaishi, 1994; 6(3): 197-202. (in Japanese)

[26] Ghahraei O, Ahmad D, Khalina A, Suryanto H, Othman J. Cutting tests of kenaf stems. Transactions of the ASABE, 2011; 54(1): 51-56.

[27] Chen Y, Gratton J L, Liu J. Power requirements of hemp cutting and conditioning. Biosyst. Eng., 2004; 87(4): 417-424. 
[28] İnce $\mathrm{A}$, Uğurluay $\mathrm{S}$, Güzel $\mathrm{E}$, Özcan $\mathrm{M} \mathrm{T}$. Bending and shearing characteristics of sunflower stalk residue. Biosyst. Eng., 2005; 92(2): 175-181.

[29] Gao G H, Wang T B, Zhou Z C, Bu Y L. Optimization experiment of influence factors on greenhouse vegetable harvest cutting. Transactions of the CSAE, 2015; 31 (19): 15-21. (in Chinese)
[30] Du D D, Wang J, Qiu S S. Optimization of cutting position and mode for cabbage harvesting. Transactions of the CSAE, 2014; 30(12): 34-40. (in Chinese)

[31] Wang W W, Ma Y D, Fu L S, Cui Y J, Majeed Y. Physical and mechanical properties of hydroponic lettuce for automatic harvesting. Inf. Process. Agric., 2020. doi: 10.1016/j.inpa.2020.11.005. 